\title{
ESTILOS E ATRIBUTOS DA LIDERANÇA NO TERCEIRO SETOR
}

\section{STYLES AND ATTRIBUTES OF THIRD SECTOR LEADERSHIP}

\author{
Maria Madalena Santos Constantin Raptopoulos \\ Doutoranda em Administração de Empresas pelo IAG/PUC-Rio \\ Rio de Janeiro, RJ, Brasil \\ E-mail: madalenaraptopoulos@yahoo.com.br \\ Jorge Ferreira da Silva \\ Professor Titular do Departamento de Administração do IAG/PUC-Rio \\ Rio de Janeiro, RJ, Brasil \\ E-mail: shopshop@iag.puc-rio.br
}

\section{RESUMO}

O Terceiro Setor tem recebido expressiva atenção da mídia e de inúmeros pesquisadores nos últimos; porém, nenhum trabalho científico até o momento teve como abordagem a consolidação dos constructos estudados e divulgados recentemente e as principais conclusões a que chegaram em relação aos estilos, atributos e desafios existentes para a liderança que atua neste setor, que é o foco deste trabalho. Para isso, foram realizadas buscas em periódicos ou revistas científicas relevantes e os artigos selecionados foram tratados sob a forma de análise de conteúdo. Os resultados demonstram que os estilos de lideranças mais relacionados com o transformacional são os que se sobrepõem neste setor. Além disso, os principais desafios existentes relacionam-se a motivar os colaboradores, sustentar as reputações das organizações e criar um ambiente de colaboração, a fim de elevar o desempenho organizacional e reter o capital intelectual necessário ao cumprimento de suas missões institucionais.

Palavras-chave: Liderança. Terceiro Setor. Estudo bibliométrico.

\begin{abstract}
The Third Sector has received significant attention from the media and numerous researchers in the latter; however, no scientific work has so far focused on the consolidation of the recently studied and published constructs and the main conclusions reached regarding the styles, attributes and challenges for the leadership that operates in this sector, which is the focus of this work. Thereby, it searches were conducted in relevant and scientific journals and the selected articles were treated in the form of content analysis. The results shows that the styles of leadership most related to the transformational are those that overlap in this sector. In addition, the main challenges are to motivate employees, sustain organizations' reputations, and create a collaborative environment in order to raise organizational performance and retain the intellectual capital needed to fulfill their institutional missions.
\end{abstract}

Keywords: Leadership. Third Sector. Bibliometric study. 


\section{INTRODUÇÃO}

Segundo Tachizawa (2007) e Fernandes (1994, p. 21), a sociedade civil está dividida em três setores, a saber: Primeiro Setor, composto pelo Estado e de origem pública e finalidade pública-estatal; Segundo Setor, do qual faz parte o mercado, cujas entidades são de origem e finalidade privadas; e, o Terceiro Setor, onde atuam agentes privados que oferecem bens e serviços públicos, portanto de origens privadas, mas com finalidades públicas não-estatais.

As primeiras publicações internacionais sobre o Terceiro Setor surgiram nos EUA em 1972 e em 1973 (BROWN, 2006); mas, no Brasil, a inserção do termo ocorreu no final da década de 1970 (MONTAÑO, 2010). De acordo com Tocqueville (1977) e Fischer e Falconer (1998, p. 14), diferentemente da tradição norteamericana, em que o associativismo e o voluntariado sempre estiveram presentes, o processo que levou ao surgimento do Terceiro Setor no Brasil teve origem nos movimentos sociais, alimentado por um componente de politização, substituto daquele perfil filantrópico presente nos Estados Unidos.

Em virtude do crescimento em importância e relevância sociais e econômicas, por preencher as lacunas deixadas pelo Estado, absorver uma força de trabalho de $1,62 \%$ no Brasil a $4,36 \%$ no mundo (JOHNS HOPKINS, 2004) e somar cerca de 290 mil fundações privadas e associações sem fins lucrativos no Brasil (IBGE, 2010) com representação de cerca de 32 bilhões de reais no PIB nacional (GIFE, 2007), este setor tem recebido considerável atenção, tanto da mídia, quanto de inúmeros pesquisadores, além das próprias instituições governamentais de regulamentação, fiscalização e controle brasileiras.

Segundo Marques et al. (2015), diversas pesquisas foram realizadas e divulgadas sobre o Terceiro Setor em congressos e periódicos brasileiros de 1998 a 2013. O foco dos estudos se distribuía da seguinte forma: estratégia e gestão (38,5\%); auditoria, contabilidade, prestação de contas e accountability (30,5\%); conceituação e regulamentação (16,1\%); gestão de pessoas ( $8,1 \%)$; e, governança e sustentabilidade $(7,2 \%)$. Apesar disso, nenhum trabalho versou especificamente sobre os estilos e atributos da liderança e os desafios relacionados a estas características.

Ainda com escopo nacional, existem dois trabalhos, publicados por Soares e Melo (2010) e Pereira et al. (2013), em que a abordagem foi realizada sobre os desafios do modelo de gestão organizacional como um todo, estando mais relacionados às funções gerenciais do que às específicas da liderança executiva.

Internacionalmente, Shier e Handy (2014) elaboraram o mapeamento do campo no período de 1986 a 2010 e avaliaram 3.790 resumos contidos no ProQuest Dissertation and Thesis database, chegando à conclusão de que $80,2 \%$ dos trabalhos eram originários dos EUA.

Além disso, especificamente sobre o tema liderança no Terceiro Setor, a maioria dos trabalhos teve o interesse em avaliar as implicações dos estilos de liderança na gestão das organizações, as qualidades que definem estes estilos de liderança específicos e como eles estão relacionados às metas desejadas pelas entidades participantes deste setor. Com isso, não foi encontrado nenhum mapeamento sobre os atributos e desafios da liderança contidos em revistas e periódicos, nacionais e internacionais, de 2003 a 2018.

Diante de todo o contexto das pesquisas anteriormente realizadas e devido à importância do Terceiro Setor na economia e a relação de sua efetividade social com as características da liderança, formulou-se o seguinte problema de pesquisa: quais são os estilos, atributos e desafios existentes para a liderança que atua no Terceiro Setor, de acordo com os constructos, nacionais e internacionais, já pesquisados e publicados. A 
fim de possibilitar o estudo, foram realizados dois recortes: relevância do meio de publicação e período de publicação.

Baseado neste problema de pesquisa, o objetivo do estudo é analisar a produção científica de 2003 a 2018, nacional e internacional, relacionada aos estilos e atributos aos quais estão sujeitas as lideranças que atuam no Terceiro Setor, dados os desafios existentes no campo, a fim de mapear possíveis lacunas de pesquisas, além de gerar conhecimento para melhoria das práticas de gestão de pessoas nestas instituições.

\section{FUNDAMENTAÇÃO TEÓRICA}

\section{O Terceiro Setor}

Segundo Til (2009), o Governo é o pilar do Primeiro Setor e tem se afastado muito das atividades de bem-estar social que deveriam ofertar à sociedade. O Segundo Setor, representado pelo Mercado, também ficou aquém de alcançar objetivos de emprego com salários justos. Portanto, a fim de ocupar um pouco do espaço deixado pelos setores anteriores e atuar também em momentos de crise, surgem as parcerias do Estado com o Terceiro Setor.

Para Fernandes (1994, p.19) e Salamon e Anheier (1997), o conceito de Terceiro Setor se refere a um conjunto de organizações e iniciativas privadas que visam à produção de bens e serviços públicos, através de um terceiro personagem, não-governamental, organizado, independente, que mobiliza a dimensão voluntária do comportamento das pessoas, mesmo que apenas no conselho diretor, e que não possui finalidade lucrativa para fins de distribuição dos lucros aos colaboradores, funcionários ou voluntários.

No Quadro 1 encontram-se as principais características das categorias que compõem o Terceiro Setor no Brasil.

Quadro 1: Categorias de instituições que compõem o Terceiro Setor no Brasil

continua

\begin{tabular}{|c|l|}
\hline Categoria & \multicolumn{1}{c|}{ Definição } \\
\hline Associações & $\begin{array}{l}\text { Organizações baseadas em contratos estabelecidos entre os indivíduos para exercerem } \\
\text { atividades comuns ou defenderem interesses comuns e mútuos. São voltadas aos membros e } \\
\text { podem exercer atividades recreativas, esportivas, culturais, artísticas, comunitárias e } \\
\text { profissionais. }\end{array}$ \\
\hline $\begin{array}{c}\text { Organizações } \\
\text { filantrópicas, } \\
\text { beneficentes e de } \\
\text { caridade }\end{array}$ & $\begin{array}{l}\text { Organizações voltadas para seus clientes na promoção de assistência social, filantropia } \\
\text { empresarial e serviço social nas áreas da saúde e da educação. Diferenciam-se das anteriores } \\
\text { por seus valores intrínsecos de altruísmo, boa vontade e serviço à comunidade. }\end{array}$ \\
\hline $\begin{array}{c}\text { Organizações não- } \\
\text { governamentais } \\
\text { (ONGs) }\end{array}$ & $\begin{array}{l}\text { Organizações comprometidas com a sociedade civil, os movimentos sociais e a transformação } \\
\text { social. Diferenciam-se das duas primeiras por raramente estarem voltadas para seus próprios } \\
\text { membros e por não exercerem qualquer tipo de caridade. Defendem ideias de construção de } \\
\text { autonomia, igualdade e participação de grupos populares. }\end{array}$ \\
\hline $\begin{array}{c}\text { Fundações de } \\
\text { apoio }\end{array}$ & $\begin{array}{l}\text { São pessoas jurídicas de direito privado, sem fins lucrativos, instituídas na forma de fundações, } \\
\text { que exercem atividades sociais relacionadas à ciência, pesquisa, saúde e educação e que atuam, } \\
\text { normalmente, junto a hospitais públicos ou universidades públicas, cujo vínculo com o poder } \\
\text { público manifesta-se sob a forma de convênios ou contratos. }\end{array}$ \\
\hline
\end{tabular}


Quadro 1: Categorias de instituições que compõem o Terceiro Setor no Brasil

continuação

\begin{tabular}{|c|c|}
\hline Categoria & Definição \\
\hline $\begin{array}{l}\text { Sociedades } \\
\text { Cooperativas }\end{array}$ & $\begin{array}{l}\text { Sociedades de pessoas, com forma e natureza jurídica próprias, de ordem civil, não sujeitas à } \\
\text { falência e constituídas para prestarem serviços aos associados. Apesar de polêmica a inclusão } \\
\text { no grupo do Terceiro Setor, visto a legislação brasileira permitir, em parte, a apropriação dos } \\
\text { resultados econômico-financeiros pelos associados, já é considerada como pertencente a este } \\
\text { setor em outros países, como Portugal, por exemplo. }\end{array}$ \\
\hline $\begin{array}{c}\text { Organizações } \\
\text { sociais } \\
\text { (OSs) }\end{array}$ & $\begin{array}{l}\text { Organizações privadas constituídas por associações civis sem fins lucrativos qualificadas } \\
\text { especificamente para o atendimento ao interesse público e à realização de atividades fomentadas } \\
\text { pelo Estado nas áreas de educação, saúde, cultura, meio ambiente e pesquisa científica. Forma } \\
\text { um modelo de parceria entre o Estado e a sociedade, onde o primeiro fomenta as atividades } \\
\text { publicizadas e exerce sobre elas um controle de gestão, através da demanda por resultados, } \\
\text { consoante o atingimento de objetivos, metas e indicadores pactuados no contrato de gestão, cuja } \\
\text { prestação de contas é anual. }\end{array}$ \\
\hline $\begin{array}{l}\text { Organizações da } \\
\text { sociedade civil de } \\
\text { interesse público } \\
\text { (OSCIPs) }\end{array}$ & $\begin{array}{l}\text { Pessoas jurídicas de direito privado, sem fins lucrativos, que realizam atividades de educação, } \\
\text { saúde, assistência social, cultura, segurança alimentar e nutricional, desenvolvimento } \\
\text { sustentável, voluntariado, desenvolvimento econômico e social, entre outros estipulados na Lei } \\
\text { 9.790/99. Para isso, estabelecem termos de parcerias com o Poder Público, com a necessidade } \\
\text { de prestações de contas anuais; no entanto, possuem inúmeras vantagens regimentais em } \\
\text { relação às organizações sociais. }\end{array}$ \\
\hline $\begin{array}{c}\text { Serviços sociais } \\
\text { autônomos (SSAs) }\end{array}$ & $\begin{array}{l}\text { Entidades instituídas por lei, com personalidade jurídica de direito privado, que prestam } \\
\text { assistência ou ensino a certas categorias profissionais ou sociais e são mantidas por } \\
\text { contribuições parafiscais instituídas pela União. São exemplos dessas entidades: Sesi (Serviço } \\
\text { Social da Indústria); Sesc (Serviço Social do Comércio); Senac (Serviço Nacional de } \\
\text { Aprendizagem Comercial); Senai (Serviço Nacional de Aprendizagem da Indústria); Sebrae } \\
\text { (Serviço Brasileiro de Apoio às Micro e Pequenas Empresas); Senar (Serviço Nacional de } \\
\text { Aprendizagem Rural); Sest (Serviço Social do Transporte); Senat (Serviço Nacional de } \\
\text { Aprendizagem do Transporte); Apex-Brasil (Agência de Promoção de Exportação do Brasil) e } \\
\text { ABDI (Agência Brasileira de Desenvolvimento Industrial). }\end{array}$ \\
\hline
\end{tabular}

Fonte: Fonte: adaptada de Rodrigues (1998), Lei 9.637 (BRASIL, 1998), Lei 9.790 (BRASIL, 1999), Câmara dos

Deputados (BRASIL, 2016) e Fux et al. (2017, p. 105-109).

Por outro lado, o Terceiro Setor internacional é também identificado como setor não-lucrativo (nonprofit sector), voluntário (voluntary sector) ou de comunidade (community sector) e formado por Organizações sem fins Lucrativos (OSFL), em inglês denominadas de Nonprofit Organizations (NPOs), Nongovernmental Organizations (NGOs) ou Third Sector Organizations (TSOs). As entidades internacionais podem ser associadas às nacionais conforme demonstrado no Quadro 2. 
Quadro 2: Associação entre categorias nacionais e estrangeiras

\begin{tabular}{|c|c|c|}
\hline REFERÊNCIA & NACIONAL & ESTRANGEIRA \\
\hline Associações & Associações & $\begin{array}{c}\text { Community-Based Organizations (CBOs), } \\
\text { Social Organizations (SOs) } \\
\text { ou } \\
\text { Nonprofit Social Organizations (NPSOs) } \\
\text { e } \\
\text { Foundations }\end{array}$ \\
\hline $\begin{array}{c}\text { Organizações filantrópicas, } \\
\text { beneficentes ou de caridade em } \\
\text { geral }\end{array}$ & $\begin{array}{c}\text { Organizações filantrópicas, } \\
\text { beneficentes ou de caridade em } \\
\text { geral }\end{array}$ & $\begin{array}{l}\text { Charities, Voluntary e Donee Organizations } \\
\text { (CBOs, VBOs e DBOs) } \\
\mathrm{e} \\
\text { Foundations }\end{array}$ \\
\hline $\begin{array}{l}\text { Organizações filantrópicas, } \\
\text { beneficentes ou de caridade } \\
\text { formadas por igrejas e } \\
\text { instituições religiosas }\end{array}$ & $\begin{array}{c}\text { Organizações filantrópicas, } \\
\text { beneficentes ou de caridade } \\
\text { formadas por igrejas e instituições } \\
\text { religiosas }\end{array}$ & $\begin{array}{l}\text { Faith-Based Organizations } \\
\text { (FBOs) }\end{array}$ \\
\hline $\begin{array}{c}\text { Organizações não- } \\
\text { governamentais (ONGs) }\end{array}$ & $\begin{array}{l}\text { Organizações não-governamentais } \\
\text { (ONGs) }\end{array}$ & Nongovernmental Organizations (NGOs) \\
\hline $\begin{array}{l}\text { Organizações sociais } \\
\text { (OSs) }\end{array}$ & $\begin{array}{l}\text { Organizações sociais } \\
\text { (OSs) }\end{array}$ & - \\
\hline $\begin{array}{l}\text { Organizações da Sociedade Civil } \\
\text { de Interesse Público (OSCIPs) }\end{array}$ & $\begin{array}{l}\text { Organizações da Sociedade Civil } \\
\text { de Interesse Público (OSCIPs) }\end{array}$ & $\begin{array}{l}\text { Public Benefit Entities } \\
\text { (PBEs) }\end{array}$ \\
\hline Fundações de apoio & Fundações privadas & - \\
\hline Sociedades Cooperativas & Sociedades Cooperativas & $\begin{array}{l}\text { Co-operatives Societies } \\
\text { (CSs) }\end{array}$ \\
\hline $\begin{array}{c}\text { Serviços Sociais Autônomos } \\
\text { (SSAs) }\end{array}$ & $\begin{array}{c}\text { Serviços Sociais Autônomos } \\
\text { (SSAs) }\end{array}$ & - \\
\hline Empresas sociais & - & Social Enterprises (SEs) \\
\hline
\end{tabular}

Fonte: adaptada de Rodrigues (1998), Lei 9.637 (BRASIL, 1998), Lei 9.790 (BRASIL, 1999), Cordery e Sinclair (2013),

Câmara dos Deputados (BRASIL, 2016) e Fux et al. (2017, p. 105-109).

Apesar de possuírem nomenclaturas iguais, as OSs e OSCIPs internacionais não são institucionalmente semelhantes às nacionais, visto que no âmbito internacional não necessariamente há uma parceria contratualizada com o Estado, bastando apenas que a organização seja sem fins lucrativos e que execute projetos e programas sociais.

Apesar da tentativa de diferenciação e delimitação de fronteiras, algumas organizações apresentam características de mais de um setor. Fernandes (1994, p. 21) já havia apontado nesta direção quando mencionou "os três setores interpenetram-se e condicionam-se de tal maneira que a definição exata dos limites é motivo de controvérsia e variações no tempo e no espaço”.

De acordo com Fischer (2002) e Brown (2006), a configuração em três setores possui intersecções em que algumas organizações se enquadram em características de mais de um setor, demonstrando o grau de desafio existente para as suas regulamentações e operações, mas, sobretudo, para as lideranças executivas que as dirigem. 


\section{Liderança em organizações do Terceiro Setor}

Segundo Kearns et al. (2015), a literatura que foca em liderança no setor sem fins lucrativos é relativamente pequena. De acordo com Moore (2000), todos os tipos de organizações, com finalidade lucrativa ou não, são criados no intuito de gerar algum tipo de valor. Entretanto, organizações lucrativas focam em estratégias para obterem ganhos financeiros e atenderem aos interesses privados, enquanto as não lucrativas e as governamentais realizam finalidades de interesse público.

Por isso, McClean (2005) menciona que líderes que atuam em organizações lucrativas são orientados ao mercado e aos seus desafios, enquanto Bear e Fitzgibbon (2005) comentam que líderes de organizações não lucrativas precisam gerenciar e equilibrar eficiência, eficácia, missão e paixão, no sentido de criar valor público e entregá-lo à sociedade com capacidade operacional e qualidade. Além disso, como muitas destas missões institucionais são vagas ou conflitantes e os recursos são escassos, os líderes precisam de competências específicas que os ajudem a vencer os desafios existentes (BEHN, 1998).

Neste sentido, a liderança dentro de organizações sem fins lucrativos é entendida como complexa em termos de comportamentos, vínculos, necessidades de grupo e objetivos. Adicionalmente, quando a diversidade e a responsabilidade da liderança, nestas instituições sem fins lucrativos, se misturam com as pressões adicionais das crises organizacionais, a complexidade se expande exponencialmente (GAJEWSKI et al., 2011).

Por esse motivo, Nanus e Dobbs (1999) descreveram as seis tarefas mais importantes para a liderança que atua em organizações sem fins lucrativos:

- Desenvolver uma visão crível e convincente junto às partes relacionadas;

- Formular uma estratégica eficaz que regule as ações e as tomadas de decisões no sentido do alcance da visão;

- Atuar como advogado e portavoz da causa a qual defende a organização;

- Construir uma relação sustentável com doadores e financiadores de recursos no sentido de alavancar a visão;

- Empoderar e inspirar os indivíduos a realizarem todos os seus potenciais humanos no sentido à realização da visão; e

- Garantir o posicionamento da organização no futuro, através da criação de alianças estratégicas com parceiros públicos e privados ou a realização de reestruturações necessárias.

Estudos recentes sobre liderança também enfatizam a necessidade de inspirar a paixão nos outros através dos atributos de visão positiva, inspiração de valores corporativos, inteligência emocional, coragem, engajamento e liderança inclusiva (BILIMORIA, GODWIN, 2005). Em particular, teorias de liderança carismática (HOUSE, 1977), transformacional (BASS, 1985) e visionária (SASHKIN, 1988) estão relacionadas a estes conceitos e têm estimulado um grande número de pesquisas e programas de treinamento de líderes.

Para Bass e Avolio (1990) e Podsakoff et al. (1990), líderes transformacionais conseguem angariar maior esforço para o desenvolvimento e a performance das organizações, porque geram compromissos dos seguidores através das dimensões de respeito, inspiração e motivação. Assim, organizações sem fins 
lucrativos, quando comparadas com organizações com finalidades lucrativas, requerem mais qualidades transformacionais para resolverem os problemas e os desafios existentes no Terceiro Setor.

Segundo Harris (1985) e Bryman (1992), líderes transformacionais são orientados para o futuro, menteaberta, dinâmicos e atuam de forma planejada, além de utilizarem seu carisma, consideração individualizada, inspiração e estimulação intelectual para alavancarem a criatividade e aprimorarem as habilidades dos empregados em suas capacidades de inovação.

Devido às características existentes nos líderes transformacionais e a forma de atuação com seus seguidores, essa relação também leva ao reino da Teoria Líder-Seguidor ou Leader-Member Exchange (LMX), na visão de Shiva e Suar (2010).

Bass e Avolio (1987) indicaram ainda que a tendência para o desenvolvimento de organizações não lucrativas é enfatizar o estilo de liderança feminina, visto as mulheres líderes tenderem a usar mais habilidades de liderança transformacional do que os homens, originando impactos positivos no desempenho dos indivíduos, dos grupos e das próprias instituições.

Por outro lado, pouco se tem associado o estilo de liderança estratégica a instituições religiosas; mas Rowe (2001) combina as características de líderes visionários e gerenciais, que é a visão de longo prazo com a necessidade de cuidar das obrigações de curto prazo, para definir o que seria esse modelo híbrido de liderança em determinadas organizações pertencentes ao Terceiro Setor.

\section{METODOLOGIA}

Para a realização da pesquisa em âmbito nacional, as buscas foram conduzidas nas bases de dados SPELL da ANPAD (http://www.spell.org.br/); Periódicos CAPES (http://www.periodicos.capes.gov.br/) e SCIELO (http://www.scielo.org/). Além disso, foram adicionadas as bases EBSCO (https://www.ebsco.com/) e Web of Knowledge (https://webofknowledge.com/) para a busca de trabalhos internacionais a respeito do tema.

Adicionalmente, à medida em que artigos relacionados ao tema iam sendo encontrados, os sites dos respectivos periódicos também eram consultados, de forma a elevar a amplitude de captação de conteúdo.

A busca se deu nos campos "Título do Documento", "Palavra-chave" e "Resumo" de cada portal, a partir das palavras a seguir mencionadas, em português e em inglês, escritas juntas: "liderança em organizações sem fins lucrativos"; "liderança em associações civis"; "liderança em organizações voluntárias"; "liderança em organizações filantrópicas"; "liderança em organizações de caridade"; "liderança em organizações baseadas na fé"; "liderança em organizações sociais"; "liderança em organizações da sociedade civil de interesse público"; "liderança em organizações não-governamentais"; e, "liderança em organizações do terceiro setor". Posteriormente, a palavra "organizações" foi trocada por "instituições" e, logo em seguida, por "entidades", tanto em português, quanto em inglês.

Foram realizados dois recortes: o primeiro em relação à relevância do meio de publicação e o segundo em relação ao período.

Em relação à relevância, foram consideradas revistas, journals e periódicos com classificação Qualis 2013-2016 da Capes avaliados como A1, A2 e B1 e/ou com SCImago Journal Rank (SJR) acima de 0,3. Isso aconteceu pelo fato de algumas revistas internacionais, específicas do Terceiro Setor ou de liderança, 
consideradas relevantes para o tema desta pesquisa, não terem tido ainda nenhuma publicação de brasileiros, mas possuírem diversos trabalhos de interesse para este estudo, como a Nonprofit Management \& Leadership, Nonprofit and Voluntary Sector Quarterly e a Leadership \& Organization Development Journal, por exemplo.

Em relação ao período, foram considerados trabalhos publicados de 2003 a 2018, para que pudessem ser trazidos materiais mais atualizados sobre os constructos de pesquisa realizados. Para avaliação do exercício de 2018, o último mês de busca de trabalhos foi abril deste ano. Assim, foram obtidos como resultado da pesquisa e lidos os resumos de 159 (cento e cinquenta e nove) estudos; porém, aproveitados apenas 38 (trinta e oito) trabalhos publicados internacionalmente.

Os estudos selecionados foram lidos integralmente e as pesquisas foram categorizadas em planilha Excel contendo: nome, local de atuação e país dos autores; tipos de instituições do Terceiro Setor analisadas ou testadas; estilos de liderança mencionados; constructos pesquisados e seus inter-relacionamentos com estilos, atributos e desafios da liderança; e, nome, ano e relevância das revistas e periódicos onde os trabalhos foram publicados. De posse dos resultados, foram elaborados quadros e gráficos representativos dos achados, e selecionados as mais relevantes para divulgação neste trabalho de pesquisa.

\section{ANÁLISE DOS RESULTADOS}

A análise bibliométrica dos resultados desta pesquisa foi dividida em três subseções: características dos estudos publicados; estilos e atributos encontrados nos líderes dos trabalhos analisados; e, os principais desafios existentes para os líderes que atuam neste setor de acordo com os construtos pesquisados.

\section{Características de Pesquisa dos Estudos Realizados e Publicados no Período de 2003 a 2018}

A quantidade de trabalhos publicados anualmente é demonstrada no Gráfico 1.

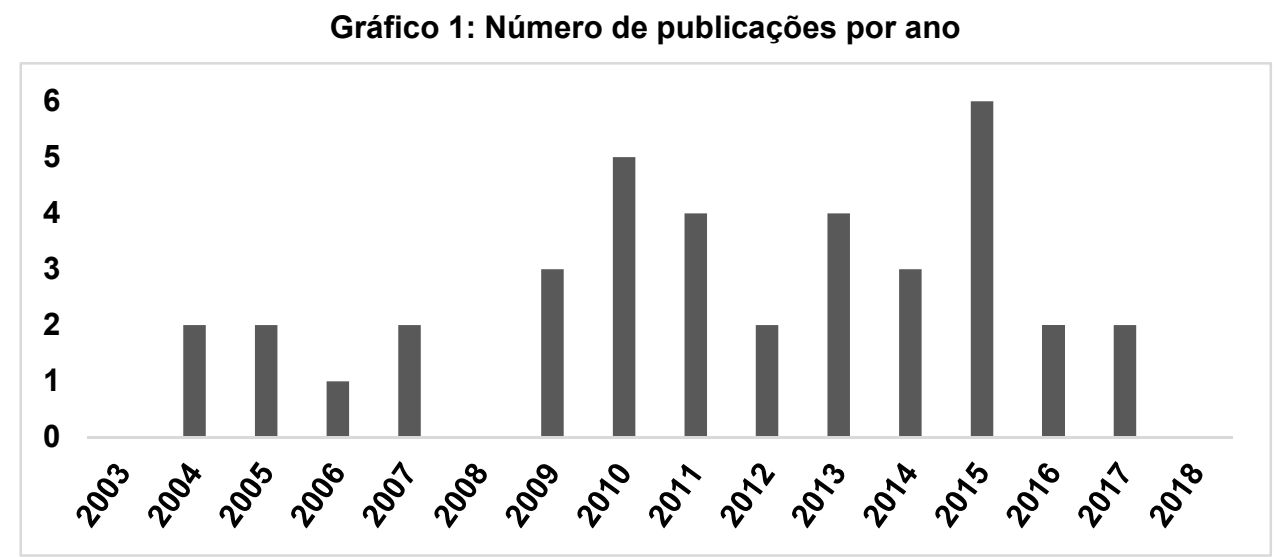

Fonte: elaborada pelos autores, com base nos resultados da pesquisa.

Os anos mais produtivos foram 2010 e 2015, sendo o período de 2009 a 2015 o mais prolífico, de acordo com o recorte realizado; O exercício de 2018 ainda não está encerrado, visto a última consulta ter sido realizada em abril. 
O Gráfico 2 demonstra a quantidade de publicações por periódico e revista, e as classificações Qualis 2013-2016 da Capes e/ou os fatores de impacto avaliados pelo SCImago Journal Rank (SJR).

Gráfico 2: Quantidade de publicações por periódico

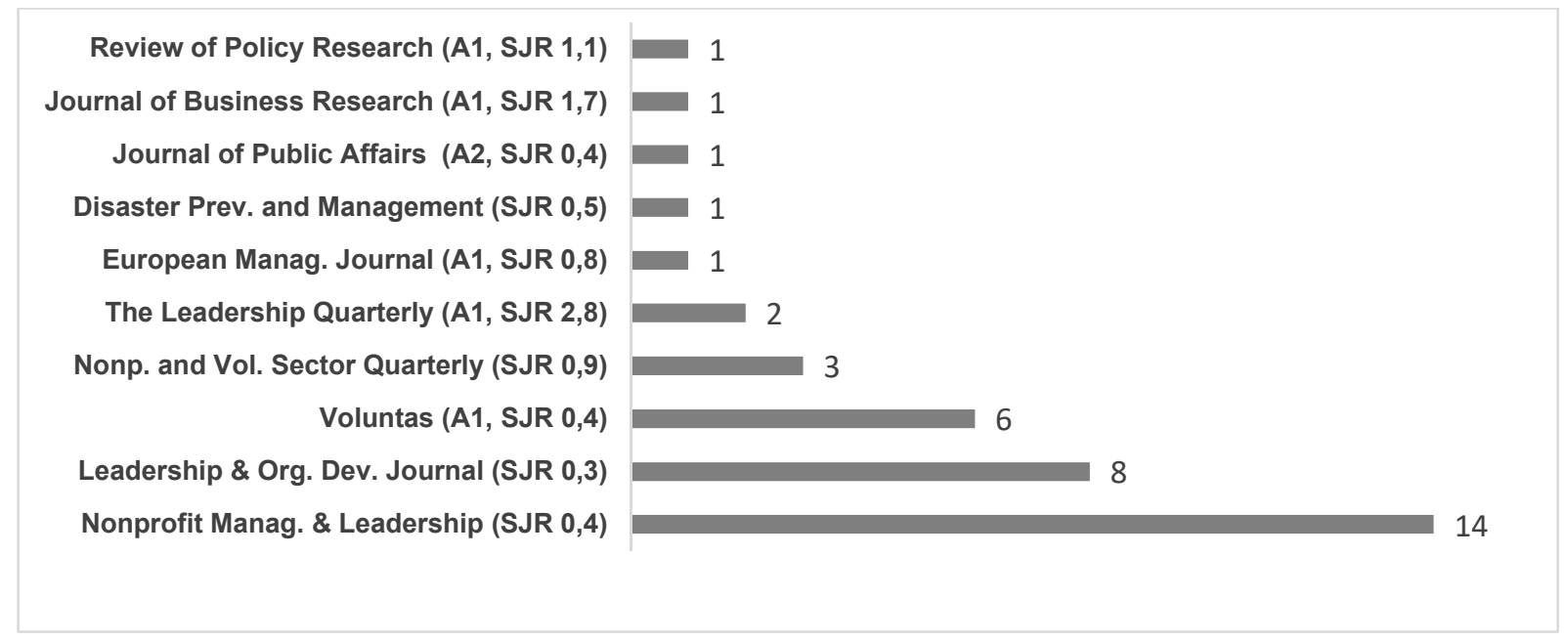

Fonte: elaborada pelos autores, com base nos resultados da pesquisa.

A representatividade por nacionalidade dos trabalhos e dos autores pode ser observada no Gráfico 3.

Gráfico 3: Representatividade por nacionalidade das pesquisas e dos autores

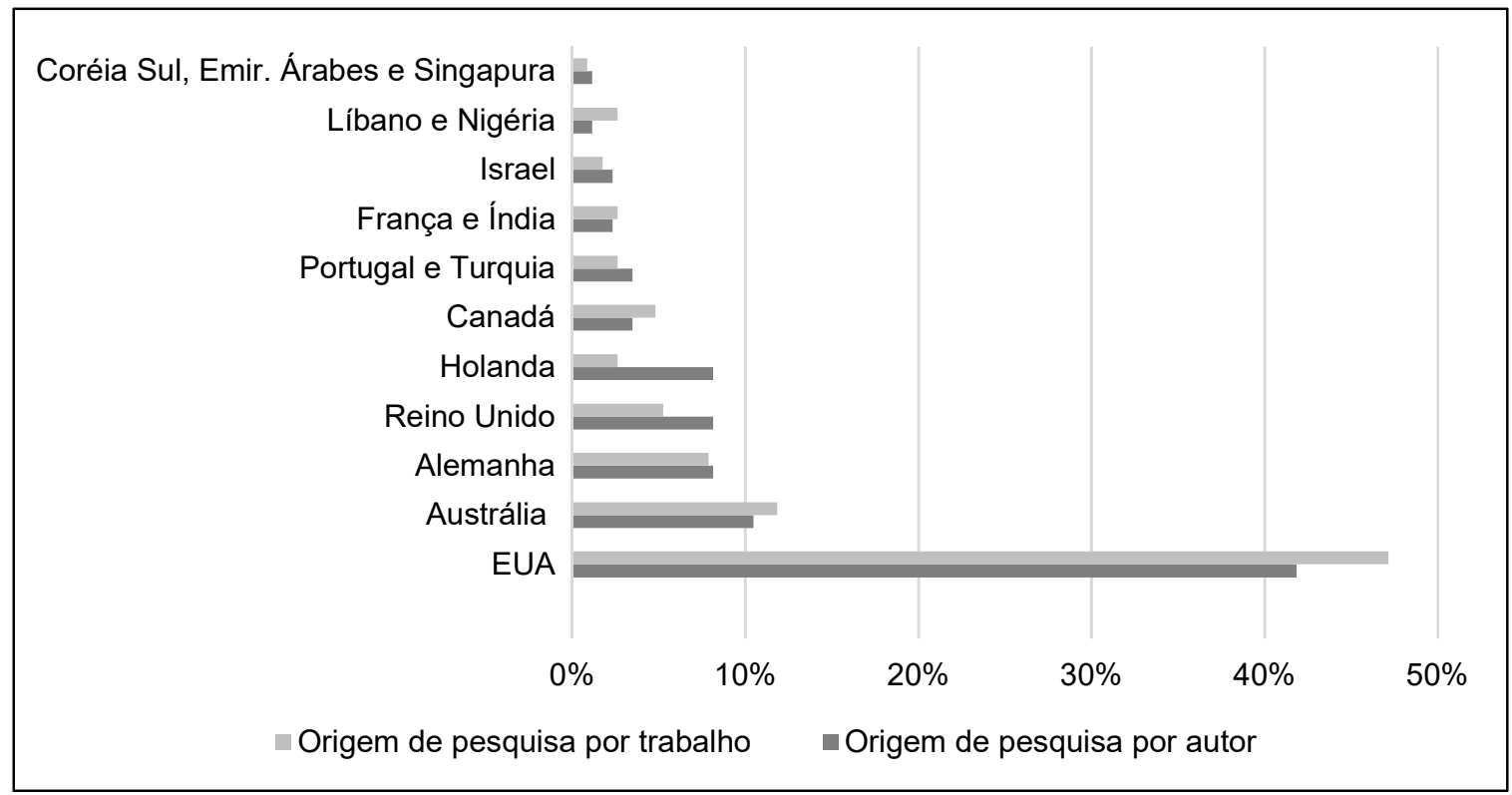

Fonte: elaborada pelos autores, com base nos resultados da pesquisa.

Estados Unidos é o país que mais publica trabalhos sobre o tema, seguido pela Austrália, Alemanha e Reino Unido, locais que contêm também o maior número de instituições pertencentes ao Terceiro Setor. Apesar da Holanda possuir um número de pesquisadores interessados no tema semelhante ao do Reino Unido e da Alemanha, todos os sete autores holandeses publicaram juntos apenas um trabalho. 
O autor mais prolífico, com três trabalhos publicados é o alemão Jens Rowold. Em seguida, com dois trabalhos cada, encontram-se: Anette Rohmann, Vic Murray, Yvonne Harrison e Russell Hoye, sendo que Anette publicou os dois estudos dela com Jens Rowold. Por outro lado, Vic Murray e Yvonne Harrison publicaram juntos os dois trabalhos mencionados.

Em relação aos tipos de pesquisas realizadas, apenas duas foram teóricas. As demais, todas empíricas, sendo dez qualitativas e vinte e seis qualitativas-quantitativas, visto que estas últimas trataram os dados coletados de forma primária e secundária por técnicas de interpretação qualitativa em conjugação com análises estatísticas.

\section{Estilos e Atributos das Lideranças que Atuam no Terceiro Setor Mencionados nas Pesquisas Publicadas no Período de 2003 a 2018}

De uma forma geral, todos os estilos de liderança encontrados, e descritos no Quadro 3, correlacionamse positivamente com a elevação no desempenho organizacional e, consequentemente, na efetividade das ações realizadas à sociedade e demais partes interessadas. Portanto, é uma liderança que atua fortemente no nível organizacional em relação ao desempenho, à imagem e à reputação; mas que também precisa saber agir no nível individual de mobilização e motivação de equipes e demais parceiros.

\section{Quadro 3: Estilos e atributos de liderança mencionados nas pesquisas}

continua

\begin{tabular}{|c|c|c|}
\hline Estilo de liderança & Autores dos trabalhos & Principais resultados das pesquisas \\
\hline Carismática & $\begin{array}{l}\text { Liu et al. (2015) } \\
\text { Mitchell (2015) } \\
\text { Harrison e Murray (2012) } \\
\text { Flanigan (2010) } \\
\text { Hoogh et al. (2005) }\end{array}$ & $\begin{array}{l}\text { A internalização de motivações extrínsecas em intrínsecas } \\
\text { influencia positivamente na performance organizacional, } \\
\text { assim como os valores da liderança influenciam na } \\
\text { reputação da efetividade das ações em organizações sem } \\
\text { fins lucrativos. }\end{array}$ \\
\hline Compartilhada & $\begin{array}{c}\text { Uzonwanne (2015) } \\
\text { Rowold e Rohmann } \\
\text { (2009) }\end{array}$ & $\begin{array}{l}\text { Executivos com mais de } 60 \text { anos e que atuam em } \\
\text { liderança compartilhada tendem a tomar decisões } \\
\text { dependentes. Além disso, líderes voluntários de } \\
\text { instituições de arte musical compartilham a liderança com } \\
\text { os gestores administrativos que, neste caso, são } \\
\text { remunerados. }\end{array}$ \\
\hline $\begin{array}{l}\text { Estratégica/ } \\
\text { Visionária }\end{array}$ & $\begin{array}{l}\text { Bilgin et al. (2017) } \\
\text { Taylor et al. (2014) } \\
\text { Grandy (2013) } \\
\text { Yip et al. (2010) }\end{array}$ & $\begin{array}{l}\text { Constrói cultura organizacional de compromisso com o } \\
\text { referencial religioso, a fim de criar uma identidade que } \\
\text { gera engajamento e alto desempenho dos colaboradores } \\
\text { em instituições baseadas na fé. Além disso, há correlação } \\
\text { positiva significativa entre esses estilos de liderança e a } \\
\text { percepção sobre a eficácia de organizações sem fins } \\
\text { lucrativos. }\end{array}$ \\
\hline
\end{tabular}


Quadro 3: Estilos e atributos de liderança mencionados nas pesquisas

continuação

\begin{tabular}{|c|c|c|}
\hline Estilo de liderança & Autores dos trabalhos & Principais resultados das pesquisas \\
\hline Inspiradora & $\begin{array}{l}\text { Ruvio et al. (2010) } \\
\text { Thach e Thompson } \\
\text { (2007) } \\
\text { Wallis e Dollery (2005) }\end{array}$ & $\begin{array}{l}\text { Inspiração é fundamental para motivar os colaboradores } \\
\text { que estejam em contextos de incentivos financeiros } \\
\text { mínimos ou inexistentes, mas que precisam fazer entregas } \\
\text { com qualidade aos clientes e demais partes interessadas } \\
\text { de organizações sem fins lucrativos. }\end{array}$ \\
\hline Teoria LMX & $\begin{array}{l}\text { Rowold et al. (2014) } \\
\text { Harrisson et al. (2013) } \\
\text { Bang (2011) } \\
\text { Hoye (2004 e 2006) }\end{array}$ & $\begin{array}{l}\text { A qualidade das relações entre líderes e seguidores afeta } \\
\text { positivamente o desempenho da liderança executiva em } \\
\text { organizações sem fins lucrativos. Adicionalmente, quanto } \\
\text { melhor essa relação, maior a capacidade de retenção de } \\
\text { colaboradores, devido ao aumento de satisfação com o } \\
\text { trabalho. }\end{array}$ \\
\hline \multirow{5}{*}{ Transformacional } & $\begin{array}{l}\text { Bassous (2015) } \\
\text { Rowold et al. (2014) } \\
\text { Felício et al. (2013) } \\
\text { Sarros et al. (2011) } \\
\text { Trautmann et al. (2007) } \\
\text { Jaskyte (2004) }\end{array}$ & $\begin{array}{l}\text { Atua na cultura e nos valores organizacionais a fim de } \\
\text { aumentar a capacidade de inovação, o aprendizado } \\
\text { organizacional e o desempenho. }\end{array}$ \\
\hline & $\begin{array}{l}\text { Allen et al. (2013) } \\
\text { McMurray et al. (2010) }\end{array}$ & $\begin{array}{l}\text { Atua no clima organizacional a fim de elevar a retenção de } \\
\text { capital intelectual e o desempenho. }\end{array}$ \\
\hline & $\begin{array}{l}\text { Shiva e Suar (2012) } \\
\text { Rowold e Rohmann } \\
\qquad(2009)\end{array}$ & $\begin{array}{l}\text { Influencia positivamente a Teoria LMX que, por sua vez, } \\
\text { eleva o compromisso com a organização. }\end{array}$ \\
\hline & Valero et al. (2015) & $\begin{array}{l}\text { Possui correlação positiva significativa com a resiliência } \\
\text { organizacional em situações de desastres naturais. }\end{array}$ \\
\hline & $\begin{array}{c}\text { Harris (2014) } \\
\text { Chao (2011) } \\
\text { Prouteau e Tabariés } \\
\qquad(2010)\end{array}$ & $\begin{array}{l}\text { Elevada correlação com a liderança feminina devido à } \\
\text { capacidade de união de empatia, amor, intuição e } \\
\text { dinamismo, como também por fugirem do modelo racional- } \\
\text { legal utilizado pelos homens; no entanto, ainda há uma } \\
\text { discriminação muito grande no setor, principalmente } \\
\text { naquelas instituições que movimentam grandes quantias } \\
\text { financeiras. }\end{array}$ \\
\hline
\end{tabular}

Fonte: elaborada pelos autores, com base nos resultados da pesquisa. 
Segundo Allen et al. (2013), Bassous (2015), Chao (2011) e Rowold e Rohmann (2009), a liderança transacional também possui correlação positiva com a maior parte dos constructos; no entanto, é bem menos significativa do que a transformacional. Adicionalmente, a liderança laissez-faire não apresentou correlação significativa nas pesquisas realizadas por esses mesmos autores.

Para Felício et al. (2013), as relações também variam de acordo com o contexto econômico. Em situações favoráveis, o empreendedorismo social atua de forma mais significativa para elevação de performance organizacional do que a liderança transformacional, e vice-versa.

Por fim, Kearns et al. (2015) ratificaram que as principais características dos líderes de organizações sem fins lucrativos são: gestão de mudança, planejamento estratégico e desenvolvimento de recursos humanos; mas, concluíram também que a construção de confiança é um dos atributos mais importantes para estes líderes, visto que essa característica influencia também nas habilidades de relacionamento, mediação e comunicação, que são significativamente necessárias para atuação no Terceiro Setor.

\section{Principais Desafios das Lideranças que Atuam no Terceiro Setor, Segundo as Pesquisas Publicadas no Período de 2003 a 2018}

Segundo Hodges e Howieson (2017), os principais desafios encontrados estão relacionados a manter a reputação da organização; estimular a motivação das pessoas; criar um ambiente positivo que propicie relacionamento e colaboração; estimular a inovação e o desenvolvimento de capacidades; e, reforçar a legitimidade do setor.

No entanto, quando a situação é de crise humanitária ou financeira, os desafios dos líderes ficam mais direcionados para o trabalho em equipe, a transparência com stakeholders, a agilidade nas respostas, a atuação estratégica, o equilíbrio emocional e o bom conhecimento da densidade e da dinâmica do segmento em que atuam (GILSTRAP et al., 2016; NEVER, 2011).

Outro desafio institucional é a perda de mão-de-obra, na maioria das vezes por aposentadoria, já que a maioria dos líderes se encontra na faixa de 61 a 79 anos. Também ocorrem muitos casos de movimentação para outras instituições do setor, o que positivamente eleva o networking, segundo Johnson (2009) e Stewart (2016).

\section{CONCLUSÃO}

Como esperado, os periódicos que mais publicam trabalhos sobre o assunto estão voltados a tratarem de organizações sem fins lucrativos e voluntárias; mas, um periódico muito importante para o tema liderança (Leadership \& Organization Development Journal) também tem se dedicado e divulgar trabalhos sobre liderança no Terceiro Setor.

A maior produção científica a respeito do tema foi realizada nos Estados Unidos, Austrália, Alemanha e Reino Unido ou por autores provenientes destes países, que são nações conhecidas por terem um grande número de instituições do Terceiro Setor atuantes.

No entanto, apesar do número de trabalhos encontrados, percebe-se que o volume ainda é pequeno e se concentra no período de 2009 a 2015, diminuindo bastante após esse período. Como pôde ser observado 
também, a produção acadêmica tem se concentrado entre dois a cinco artigos internacionais por ano e com nenhuma representação de autores brasileiros em periódicos nacionais ou estrangeiros.

Por isso, revistas consideradas relevantes internacionalmente para o Terceiro Setor não possuem avaliação recente no Qualis da Capes. Essa, portanto, é uma lacuna com oportunidade a ser preenchida por pesquisadores brasileiros.

Devido à baixa disponibilidade de informações, a maior parte dos estudos encontrados adotaram metodologias de pesquisas empíricas, através da conjunção de ferramentas qualitativas e quantitativas de análise, para que os dados necessários pudessem ser coletados e avaliados da maneira mais completa possível, levando em consideração as respostas dadas em entrevistas e o relacionamento com os dados secundários obtidos.

Pelos resultados obtidos, verifica-se que a liderança transformacional realmente é a mais identificada nos constructos pesquisados. Isso reforça a questão de que líderes de organizações sem fins lucrativos, que não utilizam do poder da compensação financeira, nem possuem, na maioria das vezes, facilidade de obtenção de financiamento e recebimento de doações, como também de mão-de-obra disponível, precisam utilizar outras dinâmicas de gestão e de liderança que vão além do simples ato de gerenciar.

Neste sentido, esses líderes precisam motivar e inspirar seus colaboradores e seguidores ao alcance da visão e dos objetivos institucionais das organizações. E, para isso, utilizam suas habilidades de transformação, a fim de potencializarem a relação líder-seguidor e gerarem compromisso com o desempenho, o resultado, a inovação e a criatividade, fundamentais para o sucesso nestes tipos de instituições. Por isso, a relação tão forte com a teoria LMX.

Porém, outros estilos de liderança também são encontrados e demonstram a complementariedade destas características, visto estarem voltados ao carisma, ao foco na visão, à inspiração e à estratégia. Alguns autores, inclusive, os enxergam como componentes da própria liderança transformacional.

A maior parte das organizações estrangeiras que pertencem ao Terceiro Setor é voltada ao voluntariado e isso se reflete na correlação positiva ser fraca em relação à existência do estilo de liderança transacional.

Já nos modelos nacionais, cujo percentual de voluntariado é inferior e existe maior dependência em relação a trocas remuneratórias, pode-se inferir que a liderança transacional apresente maior significância para as organizações brasileiras do que para as estrangeiras. Além disso, os próprios estudos internacionais demonstram que, dependendo do contexto econômico ou de crise, as relações dos constructos com os estilos de liderança também variam.

Por isso, qualquer aspecto que seja avaliado não pode ser observado apenas sob uma ótica de análise ou sob uma única característica. Logo, constructos que já tenham sido avaliados no contexto internacional não podem ser admitidos como adaptáveis de forma direta ao brasileiro ou a qualquer outro País.

Adicionalmente, o Brasil possui modelos organizacionais diferentes dos que existem no exterior, tais como as OSs e as OSCIPs, que reforçam a necessidade de realização de mais pesquisas nacionais e locais estrangeiras sobre o tema.

Em relação ao gênero, as mulheres são as que mais apresentam compatibilidades com o estilo de liderança transformacional devido à capacidade de união de empatia, amor, intuição e dinamismo; no entanto, ainda há uma discriminação muito grande no setor, principalmente naquelas instituições que movimentam 
grandes quantias financeiras, recebidas através de fomento do governo ou por financiamento privado, em atividades de investimento ou doação.

Uma novidade interessante é a menção à liderança compartilhada em organizações sem fins lucrativos e que junta a capacidade de liderança artística voluntária com a habilidade gerencial. Neste modelo, a liderança não pode ou não deve ser única, pois necessita unir habilidade técnica com capacidade de gestão.

Ainda sobre os atributos da liderança, as principais características que precisam ser desenvolvidas ou procuradas nos líderes que atuam no Terceiro Setor estão relacionadas a capacidades de relacionamento, comunicação, mediação, atuação estratégica, desenvolvimento de pessoas e equilíbrio emocional a fim de proporcionarem ambientes inovadores, colaborativos, motivacionais, transparentes, legítimos e que estimulem a retenção dos profissionais remunerados ou voluntários.

Adicionalmente, observa-se que no Brasil existe um grande número de instituições atuantes no Terceiro Setor relacionadas ao desvio ou ao mau uso dos recursos públicos recebidos. E, nos trabalhos encontrados não foram mencionadas pesquisas sobre estilos de lideranças relacionados a estas abordagens, por exemplo.

Portanto, além das possibilidades de estudos futuros já mencionados anteriormente, podem existir outras ainda não avaliadas por pesquisadores e estudiosos do tema e que representam novas oportunidades de exploração no campo.

Por isso, conhecer as abordagens já estudadas e as conclusões obtidas pelos autores contribui, não apenas para saber o que já foi pesquisado entre os estudiosos no tema, mas também para mapear as oportunidades de pesquisas futuras, além de propiciar uma melhoria no conhecimento sobre as práticas de liderança e que podem influir nas premissas a serem adotadas nas técnicas de recrutamento e seleção, avaliação de desempenho e capacitação dos profissionais que desejam atuar ou atuam neste segmento.

Por fim, este trabalho possui limitações, pois não foram avaliadas dissertações de mestrado e teses de doutorado nacionais ou estrangeiras já desenvolvidas sobre o tema, para que pudessem ser relacionados, analisados ou, até mesmo, reforçados, outros constructos pesquisados sobre estilos e atributos das lideranças que atuam em instituições do Terceiro Setor.

\section{REFERÊNCIAS}

ALLEN, S. L.; SMITH, J. E.; SILVA, N. Leadership style in relation to organizational change and organizational creativity: perceptions from nonprofit organizational members. Nonprofit Management \& Leadership, v. 24, n. 1, p. 23-42, 2013.

BANG, H. Leader-Member Exchange in Nonprofit Sport Organizations: The impact on Job Satisfaction and Intention to stay from the Perspectives of Volunteer Leaders and Followers. Nonprofit Management \& Leadership, v. 22, n. 1, p. 85105, 2011.

BASS, B. M. Leadership and performance beyond expectations. New York: Free Press, 1985.

BASS, B. M.; AVOLIO, B. J. The implications of transactional and transformational leadership for individual, team and organizational development. Organizational Change and Development, v. 4, n. 3, p. 231-272, 1990.

BASS, B.M.; AVOLIO, B. J. Full range leader development: manual for the multifactor leadership questionnaire. California: Mind Garden, 1987.

BASSOUS, M. What are the factors that affect worker motivation in faith-based nonprofit organizations? Voluntas, v. 26, p. 355-381, 2015.

BEAR, A. B.; FITZGIBBON, M. A. Leadership in a not-for-profit world: a mixed toolbox. In: SIMS, R. R., QUATRO, S. A. (Eds.), Leadership: Succeeding in the private, public, and not-for-profit sectors. New York: M. E. Sharp, 2005.

BEHN, R. D. What right do public managers have to lead? Public Administration Review, v. 58, n. 3, p. 209-224, 1998. 
BILGIN, Y.; BILGIN, G. D.; KILINC, I. Strategic leadership in civil society organizations: a research on Turkish charities performing international operations. Voluntas, v. 28, p. 839-863, 2017

BILIMORIA, D.; GODWIN, L. Engaging people's passion. In: SIMS, R. R., QUATRO, S. A. (Eds), Leadership: Succeeding in the Private, Public, and Not-For-Profit Sectors. New York: M. E. Sharp, 2005.

BRASIL. Lei n. ${ }^{\circ} 9.637$, de 15 de maio de 1998. Dispõe sobre a qualificação de entidades como organizações sociais, a criação do Programa Nacional de Publicização, a extinção dos órgãos e entidades que menciona e a absorção de suas atividades por organizações sociais, e dá outras providências. Diário Oficial da República Federativa do Brasil, Brasília, DF, 18 mai. 1998 e retificado em 25 mai. 1998. Disponível em: <http://www.planalto.gov.br/ccivil_03/leis/L9637.htm>. Acesso em: 03 ago. 2017.

BRASIL. Lei n. 9.790, DE 23 DE MARÇO DE 1999. Dispõe sobre a qualificação de pessoas jurídicas de direito privado, sem fins lucrativos, como Organizações da Sociedade Civil de Interesse Público, institui e disciplina o Termo de Parceria, e dá outras providências. Disponível em: < http://www.planalto.gov.br/ccivil_03/leis/L9790.htm > Acessado em 03 ago. 2017.

BROWN, E. W. (2006). Terceiro Setor: em busca de uma delimitação. In: BROWN, E. W. (org.). O Terceiro Setor em Perspectiva - Constituição, Interfaces e Operacionalização. São Paulo: Fiuza, 2006.

BRYMAN, A. Charisma and leadership in organizations. California: Sage, 1992.

CENTRO DE ESTUDOS DA SOCIEDADE CIVIL DA UNIVERSIDADE JOHNS HOPKINS (2004). Civil society sector workforce as a percent of the economically active population, 36 countries, 1995-2000. Disponível em: <http://ccss.jhu.edu/wp-content/uploads/downloads/2013/02/Comparative-data-Tables_2004_FORMATTED_2.2013.pdf> Acessado em 18 abr. 2017.

CHAO, CHIN-CHUNG (JOY). Climbing the Himalayas: a cross-cultural analysis of female leadership and glass ceiling effects in non-profit organizations. Leadership \& Organization Development Journal, v. 32, n. 8, p. 760-781, 2011.

CORDERY, C.; SINCLAIR, R. Measuring performance in the third sector. Qualitative Research in Accounting \& Management, v. 10 n. 3/4, 196-212, 2013.

FELÍCIO, J. A.; GONÇALVES, H. M.; GONÇALVES, V. DA C. Social value and organizational performance in non-profit social organizations: social entrepreneurship, leadership, and socioeconomic context effects. Journal of Business Research, v. 66, n. 2., p. 139-2.146, 2013.

FERNANDES, R. C. Privado porém público: o terceiro setor na América Latina. Rio de Janeiro: Relume-Dumará, 1994.

FISCHER, R. M. O desafio da colaboração: práticas de responsabilidade social entre empresas e o terceiro setor. São Paulo: Gente, 2002.

FISCHER, R. M.; FALCONER, A. P. Desafios da parceria governo e terceiro setor. Revista de Administração, v. 33, n. 1, p. 12-19, 1998.

FLANIGAN, S. T. Factors influencing nonprofit career choice in faith-based and secular NGOs in three developing countries. Nonprofit Management \& Leadership, v. 21, n. 1, p. 59-75, 2010.

FUX, L.; MODESTO, P.; MARTINS, H. F. Organizações sociais após a decisão do STF na ADI n 1.923/2015. Belo Horizonte: Editora Fórum Ltda., 2017.

GAJEWSKI, S.; BELL, H.; LEIN, L.; ANGEL, R. J. Complexity and instability: the response of nongovernmental organizations to the recovery of hurricane Katrina survivors in a host community. Nonprofit and Voluntary Sector Quarterly, v. 40 , n. 2 , p. $389-403,2011$.

GILSTRAP, C. A.; GILSTRAP, C. M.; HOLDERBY, K. N.; VALERA, K. M. Sensegiving, leadership, and nonprofit crises: how nonprofit leaders make and give sense to organizational crisis. Voluntas, v. 27, p. 2.787-2.806, 2016.

GRANDY, G. An exploratory study of strategic leadership in churches. Leadership \& Organization Development Journal, v. 34 , n. 7 , p. $616-638,2013$.

GRUPO DE INSTITUTOS FUNDAÇÕES E EMPRESAS (2007). IBGE calcula participação econômica do terceiro setor. Disponível em: <http://gife.org.br/ibge-calcula-participacao-economica-do-terceiro-setor/> Acessado em em 22 abr. 2017.

HARRIS, E. E. The impact of board diversity and expertise on nonprofit performance. Nonprofit Management \& Leadership, v. 25 , n. 2 , p. $113-130,2014$

HARRIS, P. R. Management in Transition. San Francisco: Jossey-Bass, 1985.

HARRISON, Y. D.; MURRAY, V. Perspectives on the leadership of chairs of nonprofit organization boards of directors: a grounded theory mixed-method study. Nonprofit Management \& Leadership, v. 22, n. 4, p. 411-437, 2012.

HARRISON, Y. D.; MURRAY, V.; CORNFORTH, C. Perceptions of board chair leadership effectiveness in nonprofit and voluntary sector organizations. Voluntas, v. 24, p. 688-712, 2013.

HODGES, J.; HOWIESON, B. The challenges of leadership in the third sector. European Management Journal, v. 35, p. 69-77, 2017. 
HOOGH, A. H. B.; HARTOG, D. N. D.; KOOPMAN, P. L.; THIERRY, H.; BERG, P. T. V. D.; WEIDE, J. G. V. D.; WILDEROM, C. P. M. Leader motives, charismatic leadership, and subordinates' work attitude in the profit and voluntary sector. The Leadership Quarterly, v. 16, 17-38, 2005.

HOUSE, R. J. A 1976 theory of charismatic leadership. In: HUNT, J. G.; LARSON, L. L. (Eds), Leadership: The Cutting Edge. Carbondale: Southern Illinois University Press, 1977.

HOYE, R. Leader-member exchanges and board performance of voluntary sport organizations. Nonprofit Management \& Leadership, v. 15, n. 1, p. 55-70, 2004.

HOYE, R. Leadership within Australian voluntary sport organization boards. Nonprofit Management \& Leadership, v. 16, n. 3, p. 297-313, 2006.

INSTITUTO BRASILEIRO DE GEOGRAFIA E ESTATÍSTICA (2010). As fundações privadas e as associações sem fins lucrativos no $\quad$ Brasil. $\quad$ Disponível em: http://www.ibge.gov.br/home/estatistica/economia/fasfil/2010/default_fundacoes_xls_nova_2010.shtm > Acessado em 10 abr. 2017.

JASKYTE, K. Transformational leadership, organizational culture, and innovativeness in nonprofit organizations. Nonprofit Management \& Leadership, v. 15, n. 2, p. 153-168, 2004

JOHNSON, J. L. The nonprofit leadership deficit: a case for more optimism. Nonprofit Management \& Leadership, v. 19, n. 3, p. 285-304, 2009.

KEARNS, K. P.; LIVINGSTON, J.; SCHERER, S.; MCSHANE, L. Leadership skills as construed by nonprofit chief executives. Leadership \& Organization Development Journal, v. 36, n. 6, p. 712-727, 2015.

LEGISLAÇÃO SOBRE O TERCEIRO SETOR. Dispositivos constitucionais, decretos-leis, leis, medidas provisórias e decretos federais sobre sociedade de utilidade pública e organização da sociedade civil de interesse público (Oscip). Câmara dos Deputados, Edições Câmara, 2016. Disponível em: < http://livraria.camara.leg.br/legislac-o-sobre-o-terceirosetor.html > Acessado em 03 ago. 2017.

LIU, G.; CHAPLEO, C.; KO, W. W.; NGUGI, I. K. The role of internal branding in nonprofit brand management: an empirical investigation. Nonprofit and Voluntary Sector Quarterly, v. 44, n. 2, p. 319-339, 2015.

MARQUES, B. A.; RODY, P. H. A.; REINA, D.; CAMPOS, G. M. Terceiro Setor: panorama das tendências de 1998 a 2013 por meio de um estudo bibliométrico. Revista Enfoque: Reflexão Contábil, v. 34, n. 2, p. 71-89, 2015.

MCCLEAN, R. K. From monopoly to competition: challenges for leaders in the deregulated investor-owned utility industry. In: SIMS, R. R., QUATRO, S. A. (Eds), Leadership: Succeeding in the Private, Public, and Not-for-profit Sectors. New York: M. E. Sharp, 2005.

McMURRAY, A. J.; PIROLA-MERLO, A.; SARROS, J. C.; ISLAM, M. M. Leadership, climate, psychological capital, commitment, and wellbeing in a non-profit organization. Leadership \& Organization Development Journal, v. 31, n. 5, p. 436-457, 2010.

MITCHELL, G. E. The attributes of effective NGOs and the leadership values associated with a reputation for organizational effectiveness. Nonprofit Management \& Leadership, v. 26, n. 1, p. 39-57, 2015

MONTAÑO, C. Terceiro setor e questão social: crítica ao padrão emergente de intervenção social. 6. ed. São Paulo: Cortez, 2010.

MOORE, M. H. Managing for value: organizational strategy in for-profit, non-profit and governmental organizations. Nonprofit and Voluntary Sector Quarterly, v. 29, n. 1, p. 183-208, 2000.

NANUS, B.; DOBBS, S. M. Leaders who make a difference: essential strategies for meeting the nonprofit challenge. San Francisco: Jossey-Bass, 1999.

NEVER, B. Understanding constraints on nonprofit leadership tactics in times of recession. Nonprofit and Voluntary Sector Quarterly, v. 40, n. 6, p. 990-1.004, 2011.

PEREIRA, R. DA S.; MORAES, F. C. C.; MATTOS JÚNIOR, A. B.; PALMISANO, A. Especificidades da gestão no terceiro setor. Organizações em Contexto, v. 9, n. 18, 2013.

PODSAKOFF, P. M.; MACKENZIE, S. B.; MOORMAN, R. H.; FETTER, R. Transformational leader behaviours and their effects on followers' trust in leader, satisfaction, and organizational citizenship behaviors. The Leadership Quarterly, v. 1, n. 2, p. $107-142,1990$

PROTEAU, L.; TABARIĖS, M. Female leadership in french voluntary associations. Voluntas, v. 21, p. 497-524, 2010.

RODRIGUES, M. C. P. Demandas sociais versus crise de financiamento: O papel do terceiro setor no Brasil. Revista de Administração Pública, v. 32, n. 5, p. 25-67, 1998.

ROWE, W. G. Creating Wealth in Organizations: The role of strategic leadership. Academy of Management Executive, v. 15 , n. 1, p. 81-94, 2001. 
ROWOLD, J.; BORGMANN, L.; BORMANN, K. Which leadership constructs are important for predicting job satisfaction, affective commitment, and perceived job performance in profit versus nonprofit organizations? Nonprofit Management \& Leadership, v. 25, n.2, p. 147-164, 2014.

ROWOLD, J.; ROHMANN, A. Transformational and transactional leadership styles, followers' positive and negative emotions, and performance in German nonprofit orchestras. Nonprofit Management \& Leadership, v. 20, n. 1, p. 41-59, 2009.

ROWOLD, J.; ROHMANN. A. Relationships between leadership styles and followers' emotional experience and effectiveness in the voluntary sector. Nonprofit and Voluntary Sector Quarterly, v. 38, n. 2, p. 270-286, 2009.

RUVIO, A.; ROSENBLATT, Z.; HERTZ-LAZAROWITZ, R. Entrepreneurial leadership vision in nonprofit vs. for-profit organizations. The Leadership Quarterly, v. 21, p. 144-158, 2010.

SALAMON, L. M.; ANHEIER, H. K. Defining the nonprofit sector: a cross-national analysis. Manchester: Manchester University Press, 1997.

SARROS, J. C.; COOPER, B. K.; SANTORA, J. C. Leadership vision, organizational culture, and support for innovation in not-for-profit and for-profit organizations. Leadership \& Organization Development Journal, v. 32, n. 3, p. 291-309, 2011.

SASHKIN, M. The Visionary Leader. In: CONGER, J. A.; KANUNGO, R. N. (Eds), Charismatic Leadership: The Elusive Factor in Organizational Effectiveness. San Francisco: Jossey-Bass, 1988.

SHIER, M. L.; HANDY, F. Research trends in nonprofit graduate studies: a growing interdisciplinary field. Nonprofit and Voluntary Sector Quarterly, v. 43, n. 5, p. 812-831, 2014.

SHIVA, M. S. A. M.; SUAR, D. Leadership, LMX, commitment and NGO effectiveness: transformational leadership, leadermember exchange, organizational commitment, organizational effectiveness and programme outcomes in nongovernmental organizations. International Journal of Rural Management, v. 6, n. 1, p. 117-150, 2010.

SHIVA, M. S. A. M.; SUAR, D. Transformational leadership, organizational culture, organizational effectiveness, and programme outcomes in non-governmental organizations. Voluntas, v. 23, p. 684-710, 2012.

SOARES, A. C. A. A.; MELO, M. C. DE O. L. Gestão do terceiro setor: uma prática social? Revista de Gestão USP, v. 17, n. 1, p. 1-11, 2010

STEWART, A. J. Exploring nonprofit executive turnover. Nonprofit Management \& Leadership, v. 27, n. 1, p. 43-58, 2016.

TACHIZAWA, T. Organizações não governamentais e terceiro setor: criação de ONG's e estratégias de atuação. 3 ed. São Paulo: Atlas, 2007.

TAYLOR, C. M.; CORNELIUS, C. J.; COLVIN, K. Visionary leadership and its relationship to organizational effectiveness. Leadership \& Organization Development Journal, v. 35, n. 6, p. 566-583, 2014.

THACH, E.; THOMPSON, K. J. Trading places: examining leadership competencies between for-profit vs. public and nonprofit leaders. Leadership \& Organization Development Journal, v. 28, n. 4, p. 356-375, 2007.

TIL, J. V. A paradigm shift in third sector theory and practice: refreshing the wellsprings of democratic capacity. American Behavioral Scientist, v. 52, n. 7, p. 1.069-1.081, 2009.

TOCQUEVILLE, A. A democracia na América. Belo Horizonte: E. Itatiaia; São Paulo: EDUSP, 1977.

TRAUTMANN, K.; MAHER, J. K.; MOTLEY, D. G. Learning strategies as predictors of transformational leadership: The case of nonprofit managers. Leadership \& Organization Development Journal, v. 28, n. 3, p. 269-287, 2007.

UZONWANNE, F. Leadership styles and decision-making models among corporate leaders in non-profit organizations in North America. Journal of Public Affairs, v. 15, n. 3, p. 287-299, 2015.

VALERO, J. N.; JUNG, K.; ANDREW, S. A. Does transformational leadership build resilient public and nonprofit organizations? Disaster Prevention and Management, v. 24, n.1, p. 4-20, 2015.

WALLIS, J.; DOLLERY, B. Leadership and economic theories of nonprofit organizations. Review of Policy Research, v. 22, n. 4, 2005

YIP, J.; TWOHILL, E.; ERNST, C.; MUNUSAMY, V. P. Leadership in faith-based nonprofits: The power of identity boundaries to bind and blind. Nonprofit Management \& Leadership, v. 20, n. 4, p. 461-472, 2010. 